\title{
Predicting Customer Churn and Retention Rates in Nigeria's Mobile Telecommunication Industry Using Markov Chain Modelling
}

\author{
Sulaimon Olanrewaju ADEBIYI ${ }^{1}$ \\ Department of Business Administration, \\ Federal University of Agriculture Abeokuta (FUNAAB) \\ PMB 2240. Abeokuta, Ogun State. Nigeria \\ email: adebiyiso@funaab.edu.ng \\ Emmanuel Olateju OYATOYE \\ Department of Business Administration, \\ University of Lagos, Akoka, Lagos. Nigeria. \\ email: eoyatoye@unilag.edu.ng \\ Joseph Nnamdi MOJEKWU \\ Department of Actuarial Science and Insurance, \\ University of Lagos, Akoka, Lagos. Nigeria. \\ email: jmojekwu@unilag.edu.ng
}

\begin{abstract}
The telecommunication industry is one of the service industries that is most affected by the problem of subscribers' churn. Although several techniques have been used to predict customer churn in developed countries, many of those studies used secondary data which are not readily available in Nigeria for researchers. This study investigates how Markov chains help in modelling and predicting the customer churn and retention rate in the Nigerian mobile telecommunication industry. The data generated through the survey were input in the Windows-based Quantitative System for Business (WinQSB) for analysis. The results reveal that in the study area MTN has the highest retention rate $(86.11 \%)$, followed by GLO (70.51\%), Airtel (67\%), and Etisalat (67.5\%). This result has implications for telecom firms' strategies for competitive advantage in particular and survival in general.
\end{abstract}

Keywords: Markov chain, customer churn, customer retention, market share, marketing strategies

JEL Classification: C3, C8, M1, M3, L1, L2 


\section{Introduction}

The study applies Markov chain modelling to predict customers' churn and retention rates in the Nigerian telecommunication industry. The telecommunication industry was chosen for this study owing to the reports that among all industries suffering from customers' churn phenomenon, this industry can be considered as being at the top of the list with an annual rate of approximately 30 percent (see, Kolajo \& Adeyemo, 2012; SAS Institute, 2000; Groth, 1999). Kotler and Keller (2006) describe churn as a situation that results in a waste of money and effort, similar to pouring water to a basket or bucket that is leaking. To avoid this scenario in the fast-growing Nigeria telecommunication industry, this study focuses on customers/subscribers of four functioning mobile services providers, namely, Airtel, MTN, Glo Mobile, and Etisalat.

The study introduces a theoretical and practical framework for applying Markov chain analysis to modelling and predicting customers' churn and retention rate in the Nigerian telecommunication industry in both the short run and the long run (i.e. equilibrium). This is done in order to guide the player in the industry as well as understand the trend of churn and retention through subscribers' experience and opinions based on their perception and the use of the services over a given period of time. Thus, this study is unique since there is dearth of extant literature on the application of operation research modelling, especially in the Nigerian business environment. The need for this type of study cannot be overemphasized since business practice in the $21^{\text {st }}$ century does not only need growth but rather a sustainable growth.

Moreover, according to De Bock and Van den Poel (2011), effective churn prediction has a positive impact upon a firm's profitability in several ways. First, identification of potential churning customers allows marketing decision makers to target marketing actions in a cost-effective manner. In the same vein, retention campaigns can be limited to a selection of customers, but they may cover a large proportion of all customers with an actual intention to switch. Second, high customer retention eases the pressure to attract a substantial number of new customers in every period. Studies have shown that the acquisition of new customers generally comes at a cost higher than keeping and satisfying the existing customer base (Reinartz and Kumar, 2003). Thus, customer acquisition and retention is a major concern for all industries. However, it is particularly strong in the highly competitive markets where many players (network providers) are competing for the same customers/subscribers with the implementation of mobile number portability (MNP) in a broadly liberalized telecommunications industry such as the Nigerian market.

In light of the above discussion, this study empirically presents an application of Markov chains to churn and retention analysis in order to guide effective 
decision-making and policy recommendations for sustainable growth in the industry. The outcome of this research effort provides telecommunication operators, vendors, the regulatory body, and other relevant establishments with strategies to manage customer churn and retention in the Nigerian market. In a considerable way too, the study would add to the existing literature on prediction of customers' churn and retention decisions. Thus, the main objective of this study is to examine the use of Markov chain modelling for customers' churn and retention rates prediction in the Nigerian telecommunication industry. The study is unique, since the data were collected from subscribers who churn or retain network subscriber identification module (SIM) instead of working on telecommunication firms' secondary data.

The next section presents the literature on the adaptation of Markov chain modelling to predicting customer churn and retention rates in the telecommunication industry. Section 3 presents the research methods for modelling primary data from subscribers through Markov chains. Section 4 describes the results of the data analysis. Section 5 presents the conclusions and the implications of the study for stakeholders.

\section{Literature Review}

\subsection{Markov Chain Modelling}

\subsubsection{Development of Markov Chain}

Markov modelling as a form of stochastic modelling is used for describing the process of sequence of probable transitions between states. In the present study, with four major GSM players (MTN, Airtel, Globacom, and Etisalat) in the Nigerian telecommunication industry, a subscriber will always prefer most a particular service provider at a particular time based on the setting and services provided and may shift his/her preference in the next period. The shift of preferences by an individual subscriber can be described as a sequence of certain states of satisfaction or otherwise with service providers (Beck and Pauker, 1983). A Markovian stochastic process has the memory-less property, which means that the future state can be predicted from the knowledge of the present state. This means that customer service experience at a particular time will highly influence the possible future state(s) of the customer and the decisions to be taken by him/her about the service providers. The decision to churn or retain any network provider is determined mostly on the knowledge of subscribers about the efficiency of a given service provider as concerns effective mobile communication. This feature is an essential property of the Markov processes (Norris, 1997). 
Markov chain models are particularly useful in business management and especially in marketing as a major functional area of any business organization. They are concerned with problems of customers' movement, both in terms of movement from one competitor to another and from one "state" to another. "State," in this context, may refer to the size/class of expenditure on a particular network provider (in terms of recharges), increasing or reducing the cost expended on rival service provider, termination of contract with a service provider, referral, or some other variables (Oyatoye, Adebiyi, and Amole, 2015). The present study is unique by exploring primary data on customers' churn and retention decision in the Nigerian telecommunication industry. Unlike the study by Oyatoye, Adebiyi, and Amole, (2015), which uses Gauss-Jordan elimination, this study uses Markov chains for modelling and analysis with the aid of WinQSB.

Markov chain models provide a useful conceptual method for analysing the changes generated by the variation of such variables. In some cases, they can also be used to predict future values (churn/market share prediction). Markov chain models, therefore, are valuable both in the study of customer churn/porting/ defection (switching of preference) and in retention. They can also be used for predicting customer movement (defection) or the market share forecast/rate of change that aid growth and development of telecommunication industry in Nigeria. In this regard, its aim is to determine what sort of service provider tends to increase in size and which are declining due to or compelled by the customer changes and directions (Collins, 1975).

This paper employs first-order Markov chains to analyse the survey data collected to obtain information about movement or the switching of subscribers as well as the market share of the network providers in the study area. Firstorder Markov chains probabilities of states depend only on the most recent states of the chain. Therefore, the Markov chain considered in the paper satisfies the following properties (Sharma, 2009; Ezugwu, Olugun, and Anieting, 2013):

(i) There are finite numbers of possible states: each subscriber can prefer most any of the four GSM network providers at any point in time. In this case, there is no fifth GSM service provider during the period of data collection for this study (that is, there is a limited number of GSM network operators).

(ii) States are both collectively exhaustive and mutually exclusive: the network providers listed assumed that no subscriber can prefer most the services of two network providers at any point in time. That is, a network provider can be preferred more than the other at any point in time, even in cases of multiple SIMs or phone users. The rate or frequency at which customers recharge each of the SIMs can be used to distinguish their preferences, since cost spent on SIM is important to network providers, being the major source of revenue to them.

(iii) The transition probabilities depend only on the current state of the system: If the current state is known, the conditional probability of the next state is 
independent of the states prior to the present state; that a subscriber will move to another service provider depends only on how he/she perceives the services received at present from the network provider(s) he or she currently patronizes.

(iv) The long-run probability of being in a particular state will be constant over time: subscribers seem to stay with a network provider for a long time.

(v) The transition probabilities of moving to alternative states in the next time period must sum to 1.0. Since the network providers are not more than four and the preferences of subscribers can only shuffle among them, the transition probabilities of moving to an alternative state in the next period will always sum to one.

\subsubsection{Discrete-Time Markov Chain}

We consider a time-homogenous model, that is, a model in which the transition probabilities are constant over time. The transition probability matrix $\mathbf{P}(t)$ contains the probabilities for the transitions. The rows of the matrix represent the most preferred network provider, while the columns stand for the future state (which they may churn to). The probabilities are denoted $\mathbf{p}_{\mathrm{ij}}$, and for each row $i$ and column $j$ they represent the probability of moving from state $i$ to state $j$.

$$
\begin{array}{ll}
\multicolumn{8}{c}{\text { MTN AIRTEL }} & \text { GLO ETISALAT } \\
\text { MTN } & 1 \\
\text { AIRTEL } & 2 \\
\text { GLO } & 3 \\
\text { ETISALAT } & 4
\end{array}\left(\begin{array}{llll}
p_{11} & p_{12} & p_{13} & p_{14} \\
p_{21} & p_{22} & p_{23} & p_{24} \\
p_{31} & p_{32} & p_{33} & p_{34} \\
p_{41} & p_{42} & p_{43} & p_{44}
\end{array}\right)
$$

Figure 2.1. Transition probability matrix for a time-homogeneous 4-state Markov model of mobile telecommunication service providers in Nigeria.

The sum of the row probabilities equals one since each preferred network (state) is independent of the other and a subscriber may switch/churn/move to any of the four states depending on his/her motivation for churn or retention drivers. The diagonals represent the probability of staying with or maintaining a particular network provider over time. A state is called absorbing when the probability of leaving the state is zero. For example, if the subscriber is dead or misplaces his/ her SIMs without reactivation, then it is an absorbing state (non-active lines).

A first-order Markov process in discrete time is a stochastic process $\mathrm{X}_{\mathrm{t}}, \mathrm{t}=1,2$, ... for which the following holds:

$$
\mathrm{P}\left(\mathrm{X}_{\mathrm{t}+1}=\mathrm{x}_{\mathrm{t}+1} / \mathrm{X}_{\mathrm{t}}=\mathrm{x}_{\mathrm{t}}, \ldots, \mathrm{X}_{1}=\mathrm{x}_{1}\right)=\mathrm{P}\left(\mathrm{X}_{\mathrm{t}+1}=\mathrm{x}_{\mathrm{t}+1} / \mathrm{X}_{\mathrm{t}}=\mathrm{x}_{\mathrm{t}}\right)
$$

In other words, only the present determines the future, the past is irrelevant. 


\section{Research Methods}

The study is a cross-sectional survey research of four global systems for mobile communication (GSM) subscribers in Lagos State. The sample includes subscribers who had churned from their network provider after the MNP implementation in April 2013. The MNP implementation period was used as the benchmark owing to the fact that this is the period that should still stimulate the most competition among the network service providers in any economy where this telecommunication is implemented.

The questionnaire was administered to four hundred and eighty subscribers in Lagos State, while only four hundred and eight copies of the questionnaire administered were filled properly and used for the Markov chain analysis. The data collected through a survey was transformed to transition probabilities matrix, which is amenable to Markov chain analysis. The assumptions, definition of notations, variables, parameters, and probabilities guiding this study are presented below.

\section{Markov Model Assumptions for Mobile Telecommunication Customers' Churn and Retention Prediction Rates}

Due to the condition of multiple SIM subscribers in Nigeria, mobile phone users do not necessarily port by leaving a particular network provider for another, but they combine SIMs of network providers because some mobile phones combine two, three, or even four SIMs, while some subscribers are comfortable with carrying about multiple phones (Oyatoye, Adebiyi, and Amole, 2015). Moreover, the cost of purchasing a SIM card, which was very high when GSM was introduced fourteen years ago (in 2001), has gone substantially down and is approaching zero naira.

Therefore, churning by mobile telecommunication subscribers is more of a switching their preference from a service provider to another among the multiple SIMs held. It mostly occurs when subscribers do not recharge or use a particular SIM but keep it, and they recharge that of the competitors. The Markov chain model adopted for customer churn and retention in this study is based on the following assumptions:

(i) There is a limited number of possible states since there is a limited number of GSM operators in Nigeria as at the time of this study, namely; MTN, Airtel, GLO, and Etisalat.

(ii) States are both collectively exhaustive and mutually exclusive. There is always a most preferred network, and they are mutually exclusive. That is to say, among the multiple SIMs that subscribers hold or that are on the market at a particular time, there is always a most preferred one in terms of meeting the telecommunication needs of subscribers, over other network providers. 
(iii) The transition probabilities of moving from one state to another depend only on the current state of the system.

(iv) The long-run probability of being in a particular state will be constant over time. This assumption is based on the theory that in the long run, mobile telecommunication operators would learn a lesson as to holding certain factors responsible for subscriber churn right in order to maintain a steady patronage and retain profitable subscribers.

(v) The transition probabilities of churning to alternative states (other GSM operators) in the next period, given the current period, would sum up to unity (1.0).

\section{Definition of Notations}

Let $\mathrm{S}_{\mathrm{i}}$ denote the preference (state) $\mathrm{i}$, where $\mathrm{i}=\mathrm{M}, \mathrm{A}, \mathrm{G}, \mathrm{E}$, the current GSM operator that a subscriber prefers most at a particular time;

Letter M is used to represent MTN.

Letter A is used to represent Airtel.

Letter $\mathrm{G}$ is used to represent Globacom.

Letter $\mathrm{E}$ is used to represent Etisalat.

$P$ represents the transition probability matrix;

$\Pi_{\mathrm{it}}$ signifies the proportion of market share controlled by GSM operator i in period t;

$\Pi_{i 0}$ represents the initial market share of GSM operator i in period 0.

Given the above definition, the proportion of market share controlled by the operators initially is:

$\Pi=\left(\Pi_{\mathrm{M} 0}, \Pi_{\mathrm{A} 0}, \Pi_{\mathrm{G} 0,}, \Pi_{\mathrm{E} 0}\right)$.

\section{Definition of Probabilities}

$\mathrm{p}_{\mathrm{ij}}$ denotes the probability that a subscriber who currently preferred a mobile telecommunication operator $\mathrm{i}(\mathrm{i}=\mathrm{M}, \mathrm{A}, \mathrm{G}, \mathrm{E})$ churns to another operator $\mathrm{j}(\mathrm{j}=\mathrm{M}$, A, G, E) in the next period of time. By this definition, when $\mathrm{i}=\mathrm{j}$, we mean that the subscriber is not churning to an alternative operator, thus retaining the network service provider and continuing the patronage.

\section{The Model (Transition Probability Matrix, P)}

The transition probability matrix, P, of the churn/retention tendencies of GSM subscribers in its abstract form is presented as: 


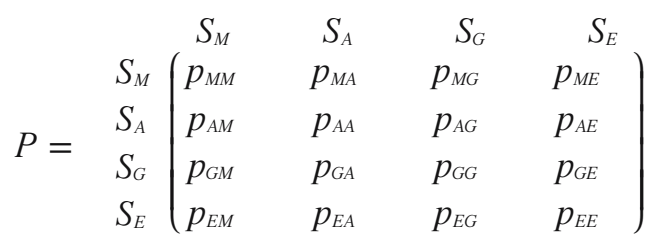

Figure 3.1. Model for subscribers' churn and retention among mobile telecommunication network operators.

\section{Results and Discussion}

To achieve the main objective (assess the use of Markov chain model for customers' churn and retention rates prediction in the Nigerian mobile telecommunication industry) of the research problem, the data collected was cross-tabulated in Table 4.1. It reveals the preferences of the respondents in the study area to GSM network operators in Nigeria. The result from the cross-tabulation was structured to suit the Markov Chain model.

Table 4.1. Cross-tabulation output

\begin{tabular}{|c|c|c|c|c|c|c|}
\hline & & \multicolumn{4}{|c|}{ To } & \multirow[b]{2}{*}{ Total } \\
\hline & & MTN & Airtel & Glo & Etisalat & \\
\hline \multirow[t]{4}{*}{ From } & MTN & 124 & 9 & 7 & 4 & 144 \\
\hline & Airtel & 22 & 71 & 9 & 4 & 106 \\
\hline & Glo & 13 & 8 & 55 & 2 & 78 \\
\hline & Etisalat & 13 & 7 & 6 & 54 & 80 \\
\hline Total & & 172 & 95 & 77 & 64 & 408 \\
\hline
\end{tabular}

Table 4.1 shows data collated from a carefully designed questionnaire aimed at understanding subscribers' behaviour in relation to the network SIM(s) they are using and the most preferred one as at the time when MNP was implemented in Nigeria. Out of the 144 subscribers that preferred MTN the most before MNP implementation, 20 show preference for other three network operators. Some 35 subscribers preferred moving from Airtel network to others, 23 from Glo, while 26 out of 80 moved to other network operators from Etisalat.

The data in Table 4.1 was used in generating a transition matrix, which is adaptable to the Markov chain modelling and analysis. In order to predict the movement of the system from one state to the next, it is necessary to know the conditional or transitional probabilities of such a movement. Thus, the data in Table 4.1 was transformed to arrive at the probability transition matrix through Table 4.2 to 4.6. The transition probability matrix enables us to predict the future 
states (market share). It helps to arrive at the probability value for the churn and retention of various network providers both in the short run and at a steady-state equilibrium.

Table 4.2. Initial table of subscribers' preference for network providers

\begin{tabular}{cccccc}
\hline Number of subscribers & Network & $\mathbf{S}_{\mathbf{M}}$ & $\mathbf{S}_{\mathrm{A}}$ & $\mathbf{S}_{\mathrm{G}}$ & $\mathbf{S}_{\mathrm{E}}$ \\
\hline 144 & $\mathrm{~S}_{\mathrm{M}}$ & 124 & 09 & 07 & 04 \\
\hline 106 & $\mathrm{~S}_{\mathrm{A}}$ & 22 & 71 & 09 & 04 \\
\hline 78 & $\mathrm{~S}_{\mathrm{G}}$ & 13 & 08 & 55 & 02 \\
\hline 80 & $\mathrm{~S}_{\mathrm{F}}$ & 13 & 07 & 06 & 54 \\
\hline & & & & \multicolumn{2}{c}{ Source: Survey 2014 }
\end{tabular}

Table 4.3. Gain and loss immediately after MNP was implemented in April 2013

\begin{tabular}{ccccc}
\hline Network & $\begin{array}{c}\text { Number of } \\
\text { subscribers }\end{array}$ & Gain & Loss & $\begin{array}{c}\text { Number of } \\
\text { subscribers }\end{array}$ \\
\hline $\mathrm{S}_{\mathrm{M}}$ & 144 & 48 & 20 & 172 \\
\hline $\mathrm{S}_{\mathrm{A}}$ & 106 & 24 & 35 & 95 \\
\hline $\mathrm{S}_{\mathrm{G}}$ & 78 & 22 & 23 & 77 \\
\hline $\mathrm{S}_{\mathrm{E}}$ & 80 & 10 & 26 & 64 \\
\hline
\end{tabular}

Table 4.4. Gains from and losses to (customers' preference of switching)

\begin{tabular}{|c|c|c|c|c|c|c|c|c|c|c|}
\hline \multirow{2}{*}{$\begin{array}{c}\text { Telecom } \\
\text { operators }\end{array}$} & \multirow{2}{*}{$\begin{array}{l}\text { Number of } \\
\text { subscribers }\end{array}$} & \multicolumn{4}{|c|}{ Losses to } & \multicolumn{4}{|c|}{ Gains from } & \multirow{2}{*}{$\begin{array}{c}\text { Total } \\
\text { subscribers }\end{array}$} \\
\hline & & $\mathrm{S}_{\mathrm{M}}$ & $\mathbf{S}_{\mathrm{A}}$ & $\mathbf{S}_{\mathrm{G}}$ & $S_{E}$ & $\mathrm{~S}_{\mathrm{M}}$ & $\mathrm{S}_{\mathrm{A}}$ & $\mathrm{S}_{\mathrm{G}}$ & $\mathbf{S}_{\mathrm{E}}$ & \\
\hline$S_{M}$ & 144 & 0 & 09 & 07 & 04 & 0 & 22 & 13 & 13 & 172 \\
\hline $\mathrm{S}_{\mathrm{A}}$ & 106 & 22 & 0 & 09 & 04 & 09 & 0 & 08 & 07 & 95 \\
\hline $\mathrm{S}_{\mathrm{G}}$ & 78 & 13 & 08 & 0 & 02 & 07 & 09 & 0 & 06 & 77 \\
\hline $\mathrm{S}_{\mathrm{E}}$ & 80 & 13 & 07 & 06 & 0 & 04 & 04 & 02 & 0 & 64 \\
\hline
\end{tabular}

Table 4.5. Retention probabilities

\begin{tabular}{ccccc}
\hline $\begin{array}{c}\text { Telecoms } \\
\text { providers }\end{array}$ & $\begin{array}{c}\text { Number of } \\
\text { customers } \\
\text { before MNP }\end{array}$ & $\begin{array}{c}\text { Number of } \\
\text { customers lost }\end{array}$ & $\begin{array}{c}\text { Number of } \\
\text { customers } \\
\text { retained }\end{array}$ & $\begin{array}{c}\text { Probability of } \\
\text { retention }\end{array}$ \\
\hline $\mathrm{S}_{\mathrm{M}}$ & 144 & 20 & 124 & $144-\frac{20}{144}=0.8611$ \\
\hline $\mathrm{S}_{\mathrm{A}}$ & 106 & 35 & 71 & $106-\frac{35}{106}=0.6698$ \\
\hline
\end{tabular}




\begin{tabular}{ccccc}
\hline $\begin{array}{c}\text { Telecoms } \\
\text { providers }\end{array}$ & $\begin{array}{c}\text { Number of } \\
\text { customers } \\
\text { before MNP }\end{array}$ & $\begin{array}{c}\text { Number of } \\
\text { customers lost }\end{array}$ & $\begin{array}{c}\text { Number of } \\
\text { customers } \\
\text { retained }\end{array}$ & $\begin{array}{c}\text { Probability of } \\
\text { retention }\end{array}$ \\
\hline $\mathrm{S}_{\mathrm{G}}$ & 78 & 23 & 55 & $78-\frac{23}{78}=0.7051$ \\
\hline $\mathrm{S}_{\mathrm{E}}$ & 80 & 26 & 54 & $80-\frac{26}{80}=0.675$ \\
\hline
\end{tabular}

Table 4.6. Probabilities associated with gains and losses of customers Probabilities of gains and losses (row = gains and column = losses)

\begin{tabular}{llllll}
\hline $\begin{array}{l}\text { Number of } \\
\text { subscribers }\end{array}$ & \multicolumn{5}{c}{ From } \\
\cline { 2 - 6 } & Network & $\mathbf{S}_{\mathrm{M}}$ & $\mathbf{S}_{\mathrm{A}}$ & $\mathbf{S}_{\mathrm{G}}$ & $\mathbf{S}_{\mathrm{E}}$ \\
\hline 144 & $\mathrm{~S}_{\mathrm{M}}$ & $\frac{0}{144}=0$ & $\frac{22}{106}=0.20755$ & $\frac{13}{78}=0.1667$ & $\frac{13}{80}=0.1625$ \\
\hline 106 & $\mathrm{~S}_{\mathrm{A}}$ & $\frac{9}{144}=0.0625 \frac{0}{106}=0$ & $\frac{8}{78}=0.1025$ & $\frac{7}{80}=0.0875$ \\
\hline 78 & $\mathrm{~S}_{\mathrm{G}}$ & $\frac{7}{144}=0.0486$ & $\frac{9}{106}=0.08491$ & $\frac{0}{78}=0$ & $\frac{6}{80}=0.075$ \\
\hline 80 & $\mathrm{~S}_{\mathrm{E}}$ & $\frac{4}{144}=0.0278$ & $\frac{4}{106}=0.03774$ & $\frac{2}{78}=0.0256$ & $\frac{0}{80}=0$ \\
\hline
\end{tabular}

The probability of gains and losses among mobile telecommunication network providers in Nigeria after mobile number portability (MNP) implementation

\begin{tabular}{|c|c|c|c|c|}
\hline & $\mathrm{S}_{\mathrm{M}}$ & $\mathrm{S}_{\mathrm{A}}$ & $\mathrm{S}_{\mathrm{G}}$ & $\mathrm{S}_{\mathrm{E}}$ \\
\hline $\mathrm{S}_{\mathrm{M}}$ & $(0$ & 0.20755 & 0.1667 & 0.1625 \\
\hline $\mathrm{S}_{\mathrm{A}}$ & 0.0625 & 0 & 0.1025 & 0.0875 \\
\hline $\mathrm{S}_{\mathrm{G}}$ & 0.0486 & 0.08491 & 0 & 0.075 \\
\hline$S_{E}$ & 0.0278 & 0.03774 & 0.0256 & 0 \\
\hline
\end{tabular}

Where the $P_{i j}=0$ indicates that no transition from state $i$ to state $j$. Thus, the retention value of preferring a network provider in the next period is shown in Figure 4.1.

\section{The Transition Probability Matrix}

\begin{tabular}{|c|c|c|c|c|}
\hline & $\mathrm{S}_{\mathrm{M}}$ & $\mathrm{S}_{\mathrm{A}}$ & $\mathrm{S}_{\mathrm{G}}$ & $\mathrm{S}_{\mathrm{E}}$ \\
\hline $\mathrm{S}_{\mathrm{M}}$ & 0.8611 & 0.20755 & 0.1667 & 0.1625 \\
\hline $\mathrm{S}_{\mathrm{A}}$ & 0.0625 & 0.6698 & 0.1025 & 0.0875 \\
\hline $\mathrm{S}_{\mathrm{G}}$ & 0.0486 & 0.08491 & 0.7051 & 0.0750 \\
\hline $\mathrm{S}_{\mathrm{E}}$ & 0.0278 & 0.03774 & 0.0256 & 0.6750 \\
\hline
\end{tabular}

Figure 4.1. Transition probability matrix for customer churn and retention. 
The diagonal figures in the probability matrix represent the ability of each network provider to retain the present subscribers in the next period of customer transition. Thus, it reveals that MTN has the highest retention rate of 86.11 percent, followed by GLO (70.51\%), Airtel (66.98\%), and Etisalat (67.5\%). This equally represents the number of mobile phone telecommunication customers of each network provider in the first six months when MNP was implemented, which is set as a benchmark to assess the churning behaviour of subscribers in the study area $(144+106+78+80=408$ subscribers $)$. The percentage share of the operators at the initial stage is computed as:

$$
\begin{array}{ll}
\text { MTN }=\frac{144}{408}=0.3529 & \text { Airtel }=\frac{106}{408}=0.2598 \\
\text { Glo }=\frac{78}{408}=0.1912 & \text { Etisalat }=\frac{80}{408}=0.1961
\end{array}
$$

The initial market shares (vectors) of each network provider as at the launch of MNP implementation in the study area are: $\mathrm{MTN}=0.3529$, Airtel $=0.2598$, Glo $=0.1912$, Etisalat $=0.1961$. Thus, the vector was used to multiply the transition probability matrix as shown below in order to obtain the market shares of the network providers at the beginning of the second period.

$$
\left(\begin{array}{llll}
S_{M} & S_{A} & S_{G} & S_{E} \\
0.3529 & 0.2598 & 0.1912 & 0.1961
\end{array}\right)\left\{\begin{array}{lllll}
0.8611 & 0.20755 & 0.1667 & 0.1625 \\
0.0625 & 0.6698 & 0.1026 & 0.0875 \\
0.0486 & 0.08491 & 0.7051 & 0.0750 \\
0.0278 & 0.03774 & 0.0256 & 0.6750
\end{array}\right\}
$$

The data was input in the Windows-based Quantitative System for Business (WinQSB). The windows interface has a column for the number of state and the name of the problem to be solved. The problem is the prediction of customer churn and retention rate in the Nigerian mobile telecommunication industry, while the states are four in number (MTN, Airtel, Glo, and Etisalat). Period one was the subscribers' preferences output of churn and retention rates for each mobile telecommunication network service provider after the implementation of mobile number portability in Nigeria (May 2013 to October 2013).

Table 4.7. Possible outcomes in the following period(s)

\begin{tabular}{lllll}
\hline $\begin{array}{l}\text { Time (every } \\
\text { six months) }\end{array}$ & MTN & Airtel & Glo & Etisalat \\
\hline Period 1 & 0.421504 & 0.232898 & 0.188731 & 0.156867 \\
\hline Period 2 & 0.468212 & 0.215475 & 0.185097 & 0.131215 \\
\hline Period 3 & 0.500045 & 0.204104 & 0.181402 & 0.11448 \\
\hline Period 4 & 0.521758 & 0.196629 & 0.178124 & 0.103492 \\
\hline Period 5 & 0.536576 & 0.191682 & 0.175406 & 0.096335 \\
\hline Period 6 & 0.546695 & 0.188389 & 0.173255 & 0.091660 \\
\hline
\end{tabular}




\begin{tabular}{lllll}
\hline $\begin{array}{l}\text { Time (every } \\
\text { six months) }\end{array}$ & MTN & Airtel & Glo & Etisalat \\
\hline Period 7 & 0.553607 & 0.186185 & 0.171600 & 0.088606 \\
\hline Period 8 & 0.558330 & 0.184704 & 0.170353 & 0.086611 \\
\hline Period 9 & 0.561558 & 0.183704 & 0.169428 & 0.085308 \\
\hline Period 10 & 0.563764 & 0.183027 & 0.168750 & 0.084457 \\
\hline Period 11 & 0.565272 & 0.182567 & 0.168258 & 0.083901 \\
\hline Period 12 & 0.566303 & 0.182254 & 0.167903 & 0.083538 \\
\hline Period 13 & 0.567007 & 0.182254 & 0.167903 & 0.083301 \\
\hline Period 14 & 0.567488 & 0.181895 & 0.167469 & 0.083146 \\
\hline Period 15 & 0.567817 & 0.181795 & 0.167341 & 0.083044 \\
\hline Period 16 & 0.568042 & 0.181727 & 0.167251 & 0.082978 \\
\hline
\end{tabular}

The results suggest that the market share in the study area will continue to increase after a successful period (six months) for MTN, up to $56 \%$, while that of Airtel will decrease to $18 \%$, Glo to $16 \%$, and Etisalat to $8.5 \%$ in Period 9 after the implementation of mobile number portability in Nigeria. Where the changes in the successful transition were not significant, we solved for a steady-state equilibrium. This result reveals that the majority of the subscribers in the study area are likely to churn to MTN, thereby maintaining the market leadership for a long time, unless other network providers evolve appropriate strategies to win more customers and retain them.

In addition, the market share difference between Airtel and Glo may be bridged depending on the strategies used by any of the operators that set to achieve such in the future, as it may not be enough to have an edge but the ability to sustain it over time is also necessary. Since we are in the era of sustainable competitive advantage, each network operator in the market is implored to look inward to their core competencies and capabilities in order to enhance sustainable growth of the firm.

In determining the market share of telecommunication operators at steadystate equilibrium, the transition probability matrix computed from the survey, as shown previously in Table 4.7, was used for computing the steady-state vector (unknown). The steady-state equilibrium is a state where further changes in the probability value for the market share of each of the telecom operators will become insignificant (Sharma, 2009).

Therefore, WinQSB was used for solving the equations obtained in order to determine the values for the unknown variables - as a result of equating the parameters of the variables at the present state to be the same for the future state, that is, $\left(\Pi_{\mathrm{Mt}}, \Pi_{\mathrm{At},} \Pi_{\mathrm{Gt},}, \Pi_{\mathrm{Et}}\right)=\left(\Pi_{\mathrm{Mi}}, \Pi_{\mathrm{Ai}}, \Pi_{\mathrm{Gi}}, \Pi_{\mathrm{Ei}}\right) \mathrm{P}$ at the steady state (Period 33).

We arrived at values for the market share at equilibrium (as "t" increases) by solving a set of simultaneous equations given by: 
$\left(\Pi_{\mathrm{Mt}}, \Pi_{\mathrm{At}} \Pi_{\mathrm{Gt}} \Pi_{\mathrm{Et}}\right)=\left(\Pi_{\mathrm{Mi}}, \Pi_{\mathrm{Ai}}, \Pi_{\mathrm{Gi}}, \Pi_{\mathrm{Ei}}\right) \mathrm{P}$, where, $\mathrm{P}$ is the transition matrix.

Dropping the second subscript on both sides gives:

$\begin{array}{ccccccc}0.8611 \mathrm{M} & + & 0.0625 \mathrm{~A} & + & 0.0486 \mathrm{G} & + & 0.0278 \mathrm{E} \\ 0.2074 \mathrm{M} & + & 0.6698 \mathrm{~A} & + & 0.0849 \mathrm{G} & + & 0.0377 \mathrm{E} \\ 0.1667 \mathrm{M} & + & 0.1026 \mathrm{~A} & + & 0.7051 \mathrm{G} & + & 0.0256 \mathrm{E} \\ 0.1625 \mathrm{M} & + & 0.0875 \mathrm{~A} & + & 0.075 \mathrm{G} & + & 0.675 \mathrm{E} \\ \mathrm{M} & + & \mathrm{A} & + & \mathrm{G} & + & \mathrm{E}=1\end{array}$

The results obtained from the window interface of the WinQSB for unknown variables are: $\Pi_{M}=0.568528, \Pi_{A}=0.1815790, \Pi_{G}=0.167041$, and $\Pi_{E}=0.082852$. These were realized based on the data processed for the study area, using the Markov model. MTN presents an ascending trend in market share while others present a descending trend. Thus, there is need for caution in order to prevent a single operator from dominating more than $50 \%$ of the entire market share in the future. This shows that if the current developments in the industry persevere for a long time, the percentage market share of each operator will remain unchanged, unless far-reaching efforts are made by other operators to sustain and increase the rate of acquisition from subscribers' churning behaviour in the mobile telecommunication industry.

\section{Conclusions and Implications}

From the survey of the customer preference of the four operators, the initial market share vector was calculated. Using the responses of subscribers on their churn and retention possibilities, a Markov chain model was developed. Findings from the model analyses showed that MTN will maintain its leadership in the telecom industry up to the steady-state point. Other operators in the industry need to re-examine their retention strategies to be able to meet customers' needs so as to reverse the downward trend of their market share. Similarly, the churn among subscribers to operators was observed to stabilize in the ninth period, provided there is no new entrant (mobile service provider) into the industry by 2017. Thus, an average subscriber will remain with one of the existing four operators.

The Markov model was found suitable in modelling customer churn and retention both in the short run and at equilibrium state. The study enriched the operations' research and marketing literature by providing empirical evidence on the application of the Markov chain model to customers' churn and retention decision in the Nigerian telecommunication industry. Thus, the results obtained have implications for the telecom firms' strategies for competitive advantage in particular and for survival in general. 
The results gave insight into customers' movements among the service providers in the industry, thereby indicating ways to formulate appropriate marketing and organizational strategies for survival. The model developed in this study could also be adapted to any service industry where the churn and retention of customers is at stake, in order to be able to predict appropriately customers' churn and retention rate, which is the bedrock of good marketing strategies for any organization.

\section{References}

Beck, J. R.; Pauker, S. G. (1983). The Markov process in medical prognosis. Medical Decision Making 3: 419-458.

Collins, L. (1975). An Introduction to Markov Chain Analysis. Ashford Kent and London: Headley. Brothers Ltd., The Invicta Press.

De Bock, K. W; D., Van den Poel. (2011). An empirical evaluation of rotationbased ensemble classifiers for customer churn prediction. Expert Systems with Applications 38(10): 12293-12301.

Ezugwu, V. O.; Olugun, S.; Anieting, A. E. (2013). Markov chain: a stabilizer to market equilibrium mix. International Journal of Advanced Scientific and Technical Research, 3(1): 565-575.

Groth, R. (1999). Data mining: building competitive advantage. Santa Clara, CA: Prentice Hall.

Kolajo, T.; Adeyemo, A. B. (2012). Data mining technique for predicting telecommunications industry customer churn using both descriptive and predictive algorithms. Computing Information Systems \& Development Informatics Journal 3(2): 27-34.

Kotler, P.; Keller. L. (2006). Marketing Management. $12^{\text {th }}$ ed. New Jersey: Pearson Prentice Hall.

Norris, J. R. (1997). Markov chains. Cambridge: Cambridge University Press.

Oyatoye, E. O.; Adebiyi, S. O.; Amole. B. B. (2015). Modeling switching behaviour of Nigeria global system for mobile communication multiple SIMs subscribers' using Markov chain analysis. The IUP Journal of Operations Management 14(1): 7-31.

Reinartz, W. J.; Kumar, V. (2003). The impact of customer relationship characteristics on profitable lifetime duration. Journal of Marketing 67(1): 77-99.

SAS Institute. (2000). Best Practice in Churn Prediction. A SAS Institute White Paper.

Sharma, J. K. (2009). Operations research; theory and applications. $3^{\text {rd }}$ ed. India: Macmillan Ltd. 